\title{
The Effects of an Extensive Reading Program on Improving English as Foreign Language Proficiency in University Level Education
}

\author{
Mohammad Akram Alzu'bi ${ }^{1}$ \\ ${ }^{1}$ English Department, Ajloun University College, Albalqa Applied University, Jordan \\ Correspondence: Mohammad Alzu'bi, English Department, Ajloun University College, Albalqa Applied \\ University, Jordan. Tel: 96-277-565-3009. E-mail: dralzubi1978@bau.edu.jo
}

Received: October 8, 2013 Accepted: November 1, 2013 Online Published: December 5, 2013

doi:10.5539/elt.v7n1p28 URL: http://dx.doi.org/10.5539/elt.v7n1p28

The research is financed by Albalqa Applied University.

\begin{abstract}
This study aimed at investigating the impact of extensive reading on improving reading proficiency. The study tried to find the effect of ER on EFL student's reading, vocabulary and grammar. The researcher designed two instruments; a program based on the extensive reading strategy and general test. Forty-one university students who study English was purposefully chosen from several universities in the academic year 2012 and the study continued for three semesters. To establish the validity for the instruments, the method of content validity was used; the instruments were given to a jury of specialists. In addition, the reliability of the test was established. Before carrying out the experiment, a pre-test for the general reading comprehension was administrated. By the end of the experiment, the researcher administrated the general reading comprehension post-test. The researcher used the t-test to detect any significant differences between the pre-test and post-test on the reading, grammar, and vocabulary. The findings show that ER improves university EFL students' reading, vocabulary and grammar achievement. Finally, the researcher suggested several recommendations.
\end{abstract}

Keywords: extensive reading, reading proficiency, writing, grammar accuracy, vocabulary

\section{Introduction}

Reading comprehension, reading speed, grammar, and vocabulary knowledge are the basic criteria often used to judge Jordanian university students' proficiency. A student who reads without comprehension is not really reading. However, comprehension will become valueless if reading efficiency does not take into account reading speed, which is usually measured in the number of words read per minute.

One series problem in reading comprehension is that among students are used to comprehending a passage on sentence level rather than on discourse level. This frailer causes some students to be dependent on understanding every single sentence in a text, even when this is not necessary to fulfill their reading purpose, with the result they tend to rend all texts at the same speed. In addition, the student heavily relies on dictionaries to get the meanings of some new words.

The intensive reading approach refers to Grammar Translation Method. Teachers adopts the intensive reading approach usually focus their attention on knowledge of English, not on the use of English. In class, they spend most of the time on sentence translation and grammar explanation. Most of the students' time is spent in translation sentences from Arabic into English, or vice versa, and in doing grammar exercise. Therefore, students fail to get as much comprehensible input in their learning process. In addition, grammar is taught deductively by using the intensive method so students have not learnt grammar meaningfully. However, extensive reading has been much neglected or it is applied in wrong way.

Hafiz and Tudor (1989) define ER as "the reading of large amounts of material in the second language over time for personal pleasure or interest, and without the addition of productive tasks or follow up language work". Grabe (1991) uses the term "sustained silent reading", while Mason and Krashen (1997) call it "free reading". In the past decades, some studies were conducted on the significance of extensive reading to foreign language or second language learning. Many of the studies show that extensive reading can effectively improve students' reading proficiency in foreign language or second language learning (Anderson, et al., 1988). 
Due to these problems caused by the difficulties of intensive reading in Jordan and based on the benefits reported by many researchers about using extensive reading, it is essential to examine whether extensive reading might be more effective than the conventional method traditionally used in EFL classroom context at Jordanian universities' levels.

In the researcher opinion, students read without any particular strategies for remembering new words, getting the main ideas, getting the meaning by the context, recognizing and applying grammar or reading in discourse level. Therefore, they do not comprehend what they are reading, and consequently they gain little information. English Department instructors still stick to the intensive reading approach instead of extensive approach. Therefore, the study focuses on examining the impact of the ER on Jordan universities students' reading comprehension achievement, grammar and vocabulary knowledge in English.

\subsection{Statement of the Problem}

In EFL countries such as Jordan, the amount of contact that English students have in language class is insufficient and they read slowly. Also, they have little chance to encounter the variety of usages of the frequent lexical and grammatical elements. ER is a useful strategy for students to have exposure to natural English in contexts they can understand. The researcher conducted the study to investigate the impact of ER on improving EFL proficiency in Jordanian Universities.

\subsection{The Questions of the Study}

The study tried to answer the following questions:

1) What is the effect of ER on EFL student's reading?

2) What is the effect of ER on EFL student's vocabulary?

3) What is the effect of ER on EFL student's grammar?

\subsection{Study Objectives}

In this work, the researcher introduced an extensive reading (ER) program into the English language curriculum in Jordan University level education. He focused on the characteristics and the benefits of ER program, and suggested how the program can improve and stimulate the learning environment while increasing learners' confidence and to find out if the learners would discover a renewed sense of enjoyment and motivation while studying English by ER strategy. He also attempted to explore the current role of ER in improving language proficiency (reading proficiency, word knowledge, and grammar). This study is conducted to find the impact of ER on improving the following dependant variables:

1) Reading comprehension

2) Vocabulary

3) Grammar

\subsection{Importance of the Study}

The study provides other researchers with some reliable instruments, action procedures, and experimental findings for use in future research. To the researcher's knowledge, there are nor studies about the effect of ER on reading, grammar and vocabulary in the context of the Arab world in particular in university level. Most of the studies were conducted on the effect of ER on reading proficiency or the effect of ER on other skills separately. However, most of the related studies approve that using ER in teaching foreign language skills has proved to be effective in most of the cases.

\subsection{Study Procedures}

This study was conducted at the first semester of the academic year 2012 and it was finished at the summer semester. The researcher adopted the following procedures:

1) Getting the approval of the selected universities to conduct the study.

2) Drawing a sample of the study from Jordanian universities.

3) Preparing the reading program which was taught to the experimental group and ensuring its validity.

4) The duration of ER course was during the first semester, second semester and summer semester of the academic year 2012. Oxford Series was available for the students to select from at their level.

5) Constructing the pre- / post-test and ensuring its validity and reliability,

6) Administrating pre-test to the group of the study to measure their reading comprehension, grammar and 
vocabulary before applying the program.

7) The group was taught by the researcher who had over 12 years of experience in TEFL.

8) Conducting the experiment and contacting the group regularly to m overcome any difficulties or problems that may appear during the implementation of the program.

9) Post-testing the group to measure their reading comprehension, grammar, and vocabulary learning.

10) Analyzing the obtained data.

\subsection{Review and Analysis of Related Study}

There are several studies concentrated on the effectiveness of ER. Powell (2005) claimed that ER has a useful role to play in high school English teaching at all levels. He starts reviewing the theory behind ER and giving the evidence for its advantages. After that, he conducted a study at a high school based on Extensive Reading program, and revealed that students enjoy ER, and ER improves students' ability and attitude.

Firstly, ER improves reading comprehension, and students who read extensively learn reading strategies and increase their reading rates. Shen (2008) curried out a study aimed at investigating the responses of two groups toward extensive reading in a three-month EFL college reading class. The researcher designed a survey questionnaire and the follow-up interviews to examine the following: (1) the factors attributed to a successful extensive reading program, and (2) the EFL readers' preferences regarding the classroom activities for reading extensively. The analysis of frequency of responses indicated that no single factor was chosen by the students and there was a discrepancy between learners with different proficiency levels and learning backgrounds. Some pedagogical implications and limitations were also discussed. Another study was carried out by Yamashita (2008) about the differential effects of extensive reading on different aspects of foreign/second language ability (reading ability and linguistic ability). The results found that the effects of extensive reading might be manifested more quickly in general reading skills than in L2 linguistic ability, at least for adult L2 learners.

Kargar (2012) carried out a study aimed at examining the effect of Extensive Reading Project on Iranian low-level learners. Sixty seven EFL students were divided randomly into one experimental and one control group. A pre-test was applied to confirm that both groups are equivalent. Then, during the treatment which took ten weeks, participants of the experimental group were asked to read ten interesting stories in English as a part of their reading class, while the members of control group continued their traditional reading class. At the end, the same test, as post-test, was introduced to both control and experimental groups. The findings revealed that ER affected on the reading proficiency achievement of low-level EFL students. Also, Bell (2001) Claims that ER may improve learner's reading speeds. The sample of the study consisted of Yemen Arab Republic on young adult students working in various government ministries. It measured both reading speeds and comprehension in two groups of learners exposed to "intensive" and "extensive". The results indicated that students who exposed to "extensive" reading achieved faster reading speeds and higher scores on measures of reading comprehension.

Secondly, there are few studies that focus on the role of ER in improving writing and vocabulary (Elley \& Mangubhai, 1981). For example, Cho and Krashen (1994) claimed that ER increased ESL learners competence in writing ability. In addition, Tan (1998) conducted a study aimed at investigating the significance of extensive reading to improving College English students' reading, listening and writing proficiencies and linguistic knowledge (grammar and vocabulary). The researcher used three instruments. The results of the studies revealed that ER can effectively improve students reading proficiency and linguistic knowledge but it is not very effective in improving students; listening and speaking proficiencies. Also, Rosszell (2007) conducted a study to examine the impact of extensive reading and intensive on vocabulary. The sample of the study consists forty intermediate level Japanese university EFL students for one semester study. The students are taught under two conditions: extensive reading with (ER+) and without (ER). The students who are in the ER+ condition were assigned 10 words from their reading to study each week, and those in ER condition completed a shortly weekly report. Participants completed two pre-, post-, and follow-up tests on the words from each reader. The findings revealed a statistically significant and sustained advantage for the ER+ group on both vocabulary measures.

Thirdly, M. Alqadi and H. Alqadi (2013) carried out a study aimed at determining the degree of the effect of ER on developing the grammatical accuracy of the EFL freshmen at Al-al-Bayt University. The population of the study consists (158) freshmen students and a sample of sixty male and female students was selected and distributed in two groups: the experimental group and the control group; each group consisted of thirty students. The students in the two groups were given a writing test in which a short paragraph was required to be written. Then the researchers started to assign several extensive reading tasks of various topics in the experimental group. After a period of 6 weeks in the second semester of the academic year 2011/2012, the subjects in both groups 
were given the same test. The two tests (pre and post) were corrected and the researchers compared their results in order to measure the effect of the treatment, which is extensive reading, on the students' writing grammatical accuracy. The scores' mean value and standard deviation in each group were calculated. The finding showed that extensive reading had a positive impact on enhancing the grammatical accuracy of the EFL freshmen at Al al-Bayt University.

Finally, Chen, et al. (2013) investigated the effectiveness of ER of e-books on EFL students' attitude, reading comprehension and vocabulary. Eighty-nine participants were assigned in two groups. Forty six students are selected in the experimental group and forty three students were selected in the control group. In addition to a traditional curriculum for both groups, a ten-week e-book extensive reading program was conducted for the experimental group by encouraging students to read the materials freely from three e-book library collections categorized on the basis of level of difficulty. Stokmans's Reading Attitude questionnaire and TOEFL reading comprehension and vocabulary test were employed to collect the data. The findings of the study showed that the experimental group affected on reading attitude, reading comprehension and vocabulary positively rather than the control group. Therefore, integrating e-books extensive reading program into EFL teaching program improved EFL students' reading attitude, reading comprehension and vocabulary.

\section{Method}

\subsection{Subjects of the Study}

The population of the study was chosen from university EFL students of English in Jordan. The sample of the study consists of forty one students who study reading comprehension, grammar, and vocabulary by using ER Method.

\subsection{Study Instruments}

To achieve the purposes of the study, the researcher used the following instruments:

1) A comprehensive reading comprehension test (as pre-post test) was designed to measure the reading comprehension, the vocabulary learning, and the structures.

2) The instructional program based on ER.

\section{First: The General Exam}

The researcher prepared the test to measure the reading comprehension, reading speed, vocabulary knowledge, and structure. Thus, the general exam contains three parts; the first group of questions measure reading comprehension and speed, the second one measures students' vocabulary knowledge, and the third group is about grammar learning. It consists 50 multiple-choice items as follows: The reading comprehension test includes 2 comprehension passages and eighteen multiple-choice items, the vocabulary achievement test includes sixteen multiple-choice items and the grammar test includes sixteen multiple-choice items.

The test measured several aspects such as figuring out the main idea in the given text, inferring the meaning of vocabulary from context, determining pronoun reference and the title of a paragraph, distinguishing the writer's style, identifying sentence order, filling in blank space with a suitable word, supplying a suitable word from one's own in a blank space, Guessing the meaning of certain lexical items, figurative expressions, phrasal verbs, idiomatic expressions and relational words from authentic reading comprehension texts, using lexical items in meaningful sentences, completing sentences by choosing the most suitable or proper words from a given list, and applying English grammar by giving examples, correcting mistakes, etc...

\section{Second: The Instructional Program}

ER Strategy Instructional Program was used to develop the reading comprehension and its speed, vocabulary and grammar learning of the experimental group. This program focused mainly on teaching ER activities and ER principles: Firstly, ER focuses on learner-centered approach so their enjoyment is generally key to the success of ER program. They also should read several topics a lot for enjoyment, information, and understanding within their ability. Also, they should use silent reading individually and read fast. Secondly, the Instructor is a model who discusses the goals of the program to students. Finally, the benefits of ER do not come in the short term and content should be relevant to the students' needs and interest.

The program aimed to promote EFL teaching through ER activities in the Jordanian text, investigate the effect of ER on EFL reading comprehension, vocabulary learning, and grammar, help EFL students to deal with reading texts away from the intervention of the teacher, create a different teacher-student relationship that would change the role students and teachers in teaching EFL teaching and learning process, develop reading speed and comprehension, vocabulary and grammar, get students interested in reading and develop the habit of independent 
reading and the sense of personal responsibility.

Description of the Instructional Program:

The study method and procedures included the instructional program. This program had the objectives of measuring the effect of ER on EFL students' reading comprehension, grammar and their vocabulary acquisition. This instructional program includes several stories and topics. The researcher selected source of material i.e. "Oxford Series" (includes seven levels) which is appropriate to be applied to the ER group because it suited the principles of ER classes, the material would meet the differing needs of the students, the reading selections included different levels so they are suitable for students' levels, the variety of the materials guaranteed a variety of vocabulary items and the topics are interesting, took care of the morals and gave useful information and sights into a variety of worldwide settings, lifestyles and perspectives.

Components of the ER program are the following:

1) The role of the instructors is to address students' motivation, teach reading strategies and check reports of students reading.

2) The role of the students is to read many selections weekly and report the number of selections they read.

3) Focus on assessment.

4) Judge the student's reading level by giving students reading comprehension test.

\subsection{Validity and Reliability of Research Instruments}

The researcher should rely on panels of experts for judgment to establish the validity of the instruments. For the present study, a cover letter was written introducing the research and asked a jury of experts to examine the content of the general reading test and check if the questions measure the reading speed, grammar and vocabulary. The validity of ER Instructional Program was assessed by giving it to a group of university specialists (EFL professors and supervisors) in public and private universities and their suggestions were taken into consideration.

To establish the reliability of the test, the researcher used the formula K-R-20 to correlate all items of this test with each other to make sure that all items correlated to each other and to make sure that all items are equivalent.

\subsection{Variables of the Study and Research Design}

The problem which was investigated involved one independent variable which is ER and three levels of dependent variable which are students' achievement in reading, vocabulary and grammar.

This study employed one of pre-experimental designs called one-group pretest-posttest design. The researcher used the experimental group that has a pre-test to measure their reading comprehension, grammar, and vocabulary before applying the program. ER strategy was applied on the group. After the treatment, the same test was administered as a posttest to detect any differences of significance between the members of the target group. The two tests were compared to investigate differences in their reading comprehension, grammar and their vocabulary. Finally, the researcher used T-test to analyze the data.

\section{Results}

\subsection{Findings Related to the First Question}

The t-test was performed to answer the first question.

Table 1. Results of t-test for the pre and post reading test

\begin{tabular}{llllllll}
\hline Skill & Test & $\mathrm{N}$ & Mean & Std. Deviation & $\mathrm{T}$ & Df & Sig.(2-tailed) \\
\hline \multirow{2}{*}{ Reading } & Pre. & 41 & 10.27 & 4.081 & -5.996 & 40 & .000 \\
& Post. & 41 & 12.589 & 3.930 & & & \\
\hline
\end{tabular}

As shown in Table 1 , there is a statistically significant difference $(\alpha \leq 0.05)$ between the pre- and post-tests attributed to the difference in the treatment(ER), in favor of the post test. It should be noted that the $\mathrm{T}$ value was $(-5.996)$. It is statistically significant at $(\alpha \leq 0.05)$. Thus, the null hypothesis which stated that there are no statistically significant differences at $(\alpha \leq 0.05)$ in the mean scores of the students' reading achievement between the two tests (pre and post-test) that was rejected. The mean score of the reading in the post-test (12.589) was 
higher than the mean score of the pre-test (10.27).

\subsection{Findings Related to Question Two}

To answer the second question, the t-test was performed.

Table 2. Results of t-test for the pre and post vocabulary test

\begin{tabular}{llllllll}
\hline Skill & Test & $\mathrm{N}$ & Mean & Std. Deviation & $\mathrm{T}$ & $\mathrm{Df}$ & Sig.(2-tailed) \\
\hline \multirow{2}{*}{ Vocabulary } & Pre. & 41 & 9.68 & 3.228 & -2.120 & 40 & .040 \\
& Post. & 41 & 10.49 & 3.716 & & & \\
\hline
\end{tabular}

As shown in Table 2, there is a statistically significant difference $(\alpha \leq 0.05)$ between the pre- and post-tests attributed to the difference in the treatment(ER), in favor of the post test. It should be noted that the $\mathrm{T}$ value was $(-2.120)$. It is statistically significant at $(\alpha \leq 0.05)$. Thus, the null hypothesis which stated that there are no statistically significant differences at $(\alpha \leq 0.05)$ in the mean scores of the students' vocabulary achievement between the two tests (pre and post-test) was rejected. The mean score of the vocabulary in the post-test (10.49) was higher than the mean score of the pre-test (9.68).

\subsection{Findings Related to the Third Question}

To answer the third question, the t-test was performed.

Table 3. Results of t-test for the pre and post grammar test

\begin{tabular}{llllllll}
\hline Skill & Test & $\mathrm{N}$ & Mean & Std. Deviation & $\mathrm{T}$ & $\mathrm{Df}$ & Sig.(2-tailed) \\
\hline \multirow{2}{*}{ Grammar } & Pre. & 41 & 9.83 & 3.353 & -2.464 & \multirow{2}{*}{40} & .018 \\
& Post. & 41 & 10.66 & 3.476 & & & \\
\hline
\end{tabular}

As shown in Table (3), there is a statistically significant difference $(\alpha \leq 0.05)$ between the pre- and post-tests attributed to the difference in the treatment(ER), in favor of the post test. It should be noted that the $\mathrm{T}$ value was $(-2.464)$ which is statistically significant at $(\alpha \leq 0.05)$. Thus, the null hypothesis which stated that there are no statistically significant differences at $(\alpha \leq 0.05)$ in the mean scores of the students' grammar achievement between the two tests (pre and post-test) was rejected. The mean score of the grammar in the post-test (10.66) was higher than the mean score of the pre-test (9.83).

\section{Discussion}

T-test was used to detect any significant differences between the two tests on the reading comprehension, grammar and vocabulary. The results revealed that the achievement of reading comprehension, grammar, and vocabulary knowledge of the students was improved.

\subsection{Discussion of the Findings Related to the First Question}

Based on the finding related to the first question, there are statistically significant differences between reading pre-test and post-test attributed to the ER program in favor of the post-test. This could be due to the following reasons; firstly, ER materials are usually stimulating and motivating learning to read and understand well because it involves a lot of pleasurable materials, easy level and variety selections. Secondly, ER improves the students' reading speed because the treatment period is long and makes the students more pleased as they read more and more. Thirdly, ER provides students with background knowledge which leads to better understand reading texts. Fourthly, ER materials are communicative and carry new thoughts and opinions that enrich EFL knowledge, Fifthly, ER makes students challenged each other and less frustrated because it allows each students to choose his favorite topic within their own capacities range. Finally, because ER increases vocabulary size and improves grammar, it affects on reading.

Few studies measure reading speeds (Bell, 2001) but there are several studies revealed that ER helps improving reading comprehension (Shen, 2008; Yamashite, 2008; Kargar, 2012; \& Chen et al, 2013). Some studies have suggested that an extensive reading (ER) program can improve of L2 learners' reading rate; Iwahori (2008) examined the effectiveness of ER on reading rates of high school students in Japan and his study found that ER 
is an effective approach to improve students' rate and general language proficiency.

\subsection{Discussion of the Findings Related to the Second Question}

Based on the finding related to the second question, there are statistically significant differences between vocabulary pre-test and post-test due to the use of ER program. The improvement in students' vocabulary attributed to repeated exposure to vocabulary item in a comprehensible input overtime that made it easier to students internalize the target words (Krashen, 1982). In addition, because of the large reading selections of several topics, the students have benefits from the variety of vocabulary items. In addition, reading pleasurable materials extensively facilitates learning vocabulary through guessing from context. Finally, the students comprehend what they read without using dictionary because ER program involves many pleasurable materials.

The long period revealed highly significant gain in vocabulary acquisition, better word recognition and selected selections are appropriate, and match the students levels o the vocabulary of the text are appropriate and easy to the students.

The findings of (Tan, 1998; Horst, 2005; Rosszell, 2007; Chun, Choi, \& Kim, 2012 \& Chen et al., 2013) revealed that ER helps improving vocabulary learning. Pigada and Schmitt (2006) investigated a study aimed at exploring whether an extensive reading program can enhance lexical knowledge and also explores how vocabulary acquisition varies according to how often words are encountered in the texts. The results showed that knowledge of $65 \%$ of the target words was enhanced. Meaning and grammatical knowledge were also enhanced. This study indicates that more vocabulary acquisition is possible from extensive reading than previous studies have suggested.

\subsection{Discussion of the Findings Related to the Third Question}

Based on the finding related to the third question, there are statistically significant differences between grammar pre-test and post-test attributed to the ER program in favor of the post-test.

The findings of Eley and Mangubhai (1981) revealed that language learning is more efficient if pupils are exposed to a wide range of structures. In addition, M. Alqadi and H. Alqadi (2013) urged that ER improves grammar. The findings of these studies are also agreed with those of (Tan, 1998; Pigada \& Schmitt 2006) which support the use of ER in EFL classroom.

\subsection{Recommendation}

1) Universities should support students and instructors with materials to apply ER program.

2) It is recommended to carry out more studies on the effect of ER on writing and speaking.

3) A study of ER over a longer period should be conducted to achieve results that are more significant.

\subsection{Conclusions}

ER improved students' vocabulary, developed good reading habit and enabled students to increase their knowledge of vocabulary and grammar. Also, ER improved students' reading comprehension achievement. In addition, ER developed better understanding of the students' language and increases culture knowledge.

\section{Acknowledgements}

This project could not have been completed without the help of Dr Bassim Abbassi (dean of scientific researchAlbalqa Applied University) so I am very glad to express my sincere appreciation to him for his encouragement and support.

\section{References}

Alqadi, M., \& Alqadi, H. (2013). The Effect of Extensive Reading on Developing the Grammatical Accuracy of the EFL Freshmen at Al Al-Bayt University. Journal of Education and Practice, 4(6).

Anderson. R., Wilson, P., \& Fielding, L. (1988). Growth in reading and how children spend their time outside of school. Reading Research Quarterly, 23, 285-303.

Bell, T. (2001). Extensive Reading: Speed and Comprehension. The Reading Matrix, 1(1). Retrieved October 28, 2006, from http://www.readingmatrix.com/archives/archives_vol1_no1.html

Chen, C. N., Chen, S. C., Chen, S. E., \& Wey, S. C. (2013). THE Effects of Extensive Reading via E-books on Tertiary Level EFL Students' Reading Attitude, Reading Comprehension and Vocabulary. TOJET, 12(2). Retrieved from http://www.tojet.net/articles/v12i2/12228.pdf

Cho, K., \& Krashen, S. D. (1994). Acquisition of vocabulary from the Sweet Valley Kids series: Adult ESL 
acquisition. Journal of Reading, 37, 662-667. Retrieved from http://eric.ed.gov/?id=EJ484772

Chun, E., Choi, S., \& Kim, J. (2012). The effect of extensive reading and paired-associate learning on long-term vocabulary retention: An event-related potential study. Neuroscience Letters, 521(2), 125-129. http://dx.doi.org/10.1016/j.neulet.2012.05.069

Elley, W. B., \& Mangubhai, F. (1981). The impact of a book flood in Fiji primary school. Wellington: New Zealand Council for Educational Research.

Grabe, W. (1991). Current developments in second language research. TESOL Quarterly, 25, 375-406. http://dx.doi.org/doi:10.2307/3586977

Hafiz, F., \& Tudor, I. (1989). Extensive reading and development of language skills. English Language Teaching Journal, 43(1), 4-13.

Horst, M. (2005). Learning L2 vocabulary through extensive reading: A measurement study. The Canadian Modern Language Review, 61(3), 355-382. http://dx.doi.org/doi:10.3138/cmlr.61.3.355

Iwahori, Y. (2008). Developing reading fluency: A study of extensive reading in EFL. Reading in a Foreign Language, 20(1).

Kargar, A. (2012). The Efficiency of Extensive Reading Project (ERP) in an Iranian EFL Context. Theory and Practice in Language Studies, 2(1). http://dx.doi.org/doi:10.4304/tpls.2.1.165-169

Krashen, S. D. (1982). Principles and practice in second language acquisition. Longman.

Mason, B., \& Krashen, S. (1997). Extensive reading in EFL. System, 25, 91-102. http://dx.doi.org/doi:10.1016/s0346-251x(96)00063-2

Pigada, M., \& Schmitt, N. (2006). Vocabulary acquisition from extensive reading: A case study. Reading in a Foreign Language, 18(1).

Powell, S. (2005). Extensive Reading and Its Role in Japanese High Schools. The Reading Matrix, 5(2).

Rosszell, H. (2007). Extensive Reading and Intensive Vocabulary Study in Japanese University. (Doctoral dissertation, Temple University, Japan). Retrieved from http://gradworks.umi.com/32/93/3293251.html

Shen, M. (2008). EFL Learners' Responses to Extensive Reading: Survey and Pedagogical Applications. The Reading Matrix, 8(2).

Tan, D. (1998). On improving College English Students' reading Proficiency at Fujian Normal University. (Published dissertation, University of Southern California).

Yamashita, J. (2008). Extensive reading and development of different aspects of L2 proficiency. System, 36(4), 661-672. http://dx.doi.org/doi:10.1016/j.system.2008.04.003

\section{Copyrights}

Copyright for this article is retained by the author(s), with first publication rights granted to the journal.

This is an open-access article distributed under the terms and conditions of the Creative Commons Attribution license (http://creativecommons.org/licenses/by/3.0/). 